Revista de Tecnología de Información y Comunicación en Educación • Volumen 15, N 1. Enero-abril 2021

DOI: https://doi.org/10.46502/issn.1856-7576/2021.15.01.13

\title{
Influence of the technical equipment on the educational process
}

\section{Influencia del equipamiento técnico en el proceso educativo}

\author{
Elena A. Ostanina \\ neka1818@mail.ru \\ $\mathrm{PhD}$ in Pedagogical Sciences, Associate Professor, Moscow Aviation Institute (National \\ Research University) Moscow, Russia \\ https://orcid.org/0000-0001-8559-5362
}

Recibido: 09/12/2020

Aceptado: 27/01/2021

\begin{abstract}
Currently, the relevance of the study is due to external global challenges, which include COVID-19 pandemic, which provoked an emergency in a number of countries. Assessment of the psychological state of participants in the educational process and its normalization can help to minimize the decline in the quality of education. The purpose of this study is to identify the possibility of organizing a high-quality distance learning process by identifying negative factors and leveling their impact during emergency situations and situations close to them. The study identified internal and external factors affecting the psychological state of teachers. The correlation between the harmony of the teacher's personality and successful labor activity has been substantiated. In the course of the work, the problem of changing the technical equipment of participants in the educational process during an emergency and close to it was revealed. As a result of the research, the author came to a well-grounded conclusion that the psychological state of the participants in the learning process has a significant impact on the educational process when organizing distance learning. The most significant in this regard is the psychoemotional state of the teacher as the organizer of the process and mentor. The article provides a number of recommendations for leveling the destabilizing factors that have a negative impact on the psychological state of the participants in the learning process and affect its quality.
\end{abstract}

Keywords: harmonization of the teacher's personality, distance learning, pandemic, psychological state, technical equipment. 


\section{Resumen}

Actualmente, la relevancia del estudio se debe a los desafíos globales externos, que incluyen la pandemia COVID-19, que provocó una emergencia en varios países. La evaluación del estado psicológico de los participantes en el proceso educativo y su normalización puede ayudar a minimizar el deterioro de la calidad de la educación. El propósito de este estudio es identificar la posibilidad de organizar un proceso de educación a distancia de alta calidad identificando factores negativos y nivelando su impacto en situaciones de emergencia y situaciones cercanas a ellos. El estudio identificó factores internos y externos que afectan el estado psicológico de los docentes. Se ha comprobado la correlación entre la armonía de la personalidad del docente y la actividad laboral exitosa. En el transcurso del trabajo, se reveló el problema de cambiar el equipo técnico de los participantes en el proceso educativo durante una emergencia y cerca de ella. Como resultado de la investigación, el autor llegó a la conclusión fundamentada de que el estado psicológico de los participantes en el proceso de aprendizaje tiene un impacto significativo en el proceso educativo al organizar el aprendizaje a distancia. El más significativo en este sentido es el estado psicoemocional del docente como organizador del proceso y mentor. El artículo ofrece una serie de recomendaciones para nivelar los factores desestabilizadores que tienen un impacto negativo en el estado psicológico de los participantes en el proceso de aprendizaje y afectan su calidad.

Palabras clave: armonización de la personalidad del docente, educación a distancia, pandemia, estado psicológico, equipamiento técnico.

\section{Introducción}

Events of the past year associated with new challenges (COVID-19 pandemic, subsequent restrictions and even severe lockdowns), unpredictability and uncertainty of the development of surrounding events, ways of interaction of all participants in the educational process and implementation of such methods through their own technical support, overload of communication networks and need to install and study of additional software, made it possible to identify the key factors influencing the learning process in general, as well as psychoemotional and motivational state of its participants. Despite the fact that during several decades a number of educational organizations have been implementing training using distance educational technologies, and the transition of the learning process to a distance format only accelerated the process of their development and implementation in the educational process, a significant number of employees of educational organizations were not ready for a total change of training format. Telecommunication networks of universities were not ready enough for it. As a result, with all the development and demand for distance educational technologies, the pedagogical community faced a number of problems.

However, the situation had the greatest impact on the direct participants in the educational process: teachers and students. Psychological state predetermined 
changes in the very process of communication during training and also affected its quality. As a result, the task of identifying the most significant factors leading to the destabilization of the psychological state of the participants in the learning process and then to its normalization came to the first plan. The hypothesis of the research is the position that the solution of the above problem during the period of instability is possible by leveling the destabilizing factors of the psychological state of the participants in the educational process with the competent organization of the learning process using distance learning technologies.

Thus, the purpose of this study is to identify the possibility of leveling the destabilizing factors of the psychological state of participants in the educational process when organizing a high-quality learning process using distance educational technologies during emergency situations and situations close to them.

Emergency educational or close to it for the educational system in the framework of this study is unplanned, time-limited transition from one form of education to another without proper provision of this process, accompanied by factors that destabilize the psychological state of the participants in the educational process.

In the course of this study, it is advisable to use the most accessible methods of collecting information under conditions of restrictions through interviewing and psychological testing using telecommunication networks. As a result, data on the state of the respondents can be obtained and recommendations for reducing the impact of destabilizing factors can be developed.

\section{Theoretical Basis}

Learning with the use of distance learning technologies involves the use of technologies implemented mainly with the use of information and telecommunication networks with indirect (at distance) interaction between students and teachers. Thus, already from the definition, the complication of the process of transferring knowledge follows, which is expressed in the need to use technical means and information and telecommunication technologies. This symbiosis presupposes the adaptation of the teacher and the student to the new realities of the process. Here it is necessary to take into account the peculiarities of the technical equipment of each of the participants, as well as in the case of distributed placement of participants and the quality of services of the university network and of a third-party organization providing telecommunications services to subscribers. As a result, the pedagogical process becomes even more multidimensional and additional factors that can have a significant impact on its quality.

The inconsistency of some parameters should also be noted. It is often almost impossible to predict the quality of communication, because if students are distributed over a large area, the above parameter becomes almost individual one. The technical means used by each participant are also, due to their characteristics, able to contribute 
to the formation of indicators of the quality of the learning process. It is impossible to visually perceive the same content on a widescreen monitor and on the screen of a smartphone or tablet. At the same time, the complexity of the implementation of practical tasks in a number of university disciplines is noted. The example of this situation is the quality of creation and full editing of the reporting material (abstract, laboratory report) using a mobile device.

Thus, the technical component makes a significant contribution to the quality of the learning process. Moreover, it is impossible to describe its influence by simple patterns. Continuous improvement of technology, use of new technologies and methods in the learning process gives a non-linear increase in the quality of education. For example, use of a virtualization environment is capable of visualizing various complex processes (chemical, biological, physical), but this requires the use of special programs and devices (3D displays, virtual glasses). The characteristics of the network and technical devices of each of the participants are important: power of the server of the educational organization, platform used to implement the process, RAM of the teacher's and students' computers, number of cores of their processors, size and characteristics of screens.

When teaching using a distance learning system at a university, as a rule, one of three models of the educational process is implemented, as well as their combinations:

- conservative, when all educational materials are given out to students in accordance with the schedule of the educational process;

- liberal, when a student or a group has access to all or to a significant part of the training materials and relevant methodological recommendations, as well as the schedule of the entire educational process. It should be noted that in this case the student has the opportunity to personally build his educational trajectory;

- adaptive, taking into account the individual characteristics of the student already at the stage of providing him with materials through the formation of individual schedule, taking into account degree of his interest and preparedness, speed of mastering the material, etc.

From the point of view of technical implementation, the liberal model turns out to be the simplest. The complexity of technical implementation of the conservative and adaptive models is approximately the same, however, the adaptive model provides undoubted advantages due to taking into account the individual characteristics of the student.

When implementing the principle of lifelong learning, the last and adaptive model can be very interesting. In this case, the built individual trajectory based on the obtained results (for example, input control of knowledge through testing) will be the most adequate and will allow getting the best learning result.

The preparation process at a university can be built using several models. So, at the initial stages of preparation, it is more expedient to use a conservative model, which 
allows students to adapt to new conditions, setting fixed time frames for completing tasks and teaching them to a discipline. Further, it is possible to use an adaptive model. Its use will give the best result, including in the course of retraining and advanced training, provided that a sufficient amount of data about the student is accumulated and used. The use of the liberal model is advisable in the presence of high motivation among students, which, unfortunately, occurs in a small proportion of the total number of students.

Thus, the technical component of the learning process in a distance format plays a very important role and can negate all the efforts of teachers and the motivation of students to study. However, the use of technical means contributes to the acquisition of additional competencies: in their use, in installing and studying new software and in solving educational problems on various devices (stationary, mobile). The active use of technical means in some way stimulated the development of competence in information retrieval in the global network, study of network technologies and information security.

Having considered the technical component of the learning process, special attention should be paid to the psychological readiness of teachers and students to implement this process using distance learning technologies. In this regard, the stressful nature of the situation is very important during the abrupt and unplanned transition from the traditional face-to-face format to the remote one.

Thus, taking into account the current situation, we can say that the problems of the psychological state of the participants in the educational process come to the first plan. If the problem of technical equipment can be leveled by leasing technical means of educational organizations to students and teachers, as well as using open-source software or access to corporate cloud spaces, it is almost impossible to neutralize the impact of psychological factors during this period. The study of the problem of psychological well-being is reflected in a number of Russian scientific works. Thus, aspects of psychological health are described by M.I. Volovikova, I.A. Dzhidaryan (Volovikova \& Dzhidaryan, 2017), I.V. Dubrovina, E.E. Danilova, A.M. Prikhozhan (Dubrovina et al., 2019), G.S. Nikiforov, (Nikiforov, 2002), the influence of psychological stress on the life of a person was studied by O.S. Deineka, G.S. Melnik, L.N. Dukhanin and A.A Maksimenko and the peculiarities of psychological well-being in conditions of uncertainty were devoted to P.A. Kislyakov, E.A. Shmeleva and O.A. Silaeva (Mikhailova \& Farennikova, 2020; Deineka et al., 2020; Kislyakov et al., 2020).

The changes that have occurred in people's lives during COVID-19 pandemic have affected all areas of life, from the possibility of routinely performing their work duties to spending leisure time and sometimes direct restrictions on leaving their homes; they were one of the key factors that had a negative impact on the psychological state of the population of Russia. People were exposed to extreme stress due to fear for their health and the health of their family and friends, uncertainty about the future, collapse of plans and contradictions in the information field. At the same time, previously habitual ways to 
deal with stress, such as visiting exhibitions, gyms, swimming pools and just a walk in the park, turned out to be unavailable. As a result of a long stay in a stressful situation, people experienced interpersonal and intrapersonal conflicts, depressed psychological state, apathy and loss of interest in further work and personal growth.

A factor that can dramatically worsen psychological well-being and lead to a state of "mass hysteria" is the phenomenon of infodemia. It is characterized by the spread in social networks and the media of diverse and questionable information about the international situation and the nature of the pandemic. Moreover, it has a different effect on people with different levels of education. The least susceptible to it are people with a high level of knowledge in a given subject area, however, they are also exposed to stress as a result of the massiveness of the phenomenon in their environment.

A survey conducted among teachers revealed the following destabilizing factors and fears:

- anxiety about health and the future, as well as about the health and future of family and friends;

- fear of the outbreak of armed conflicts of different localization;

- loss of confidence in ensuring personal rights and freedoms and possibility of interference in private life;

- uncertainty of the situation associated with the continuation of labor activity in new conditions.

In conditions of psychological stress and stress for a teacher, such personal qualities as self-control, ability to adequately assess the environment, ability to understand, empathize and activate the activities of students are extremely important. Confidence in the "tomorrow" is important, in one's strengths and knowledge (general condition, erudition, deep knowledge and love for one's subject area, knowledge of intersubject connections and related areas); courage in admitting mistakes and shortcomings; sincere belief in the success of students.

In this situation, it is very important to achieve harmonization of the individual's relations not only with various phenomena and objects of the surrounding world, but also, first of all, with himself (Ostanina \& Ostanin, 2019). As a result, a person can gain psychological health, calmness and poise, which will contribute to his professional and personal achievements, scientific and creative self-realization. One of the founders of this direction considering the activities and professional development of a teacher is the doctor of psychological sciences L.V. Abdalina (Abdalina, 2008). From the standpoint of psychology, as a science, the harmony of an object/subject can affect it, generating a variety of emotions, and even creating a certain attitude. At the same time, feelings, like "... stable emotional relationships of a person to the phenomena of reality..." (Zinchenko, 2003) can influence, cause and intensify the experience of coherence and mutual coincidence of internal and external, disharmony, rejection in perception as the surrounding world and yourself. 
Thus, the harmonization of the teacher's personality as a factor of stable and successful performance of labor functions should be considered as a process of research, development of a coordinated and adequate attitude to the phenomena and objects of the surrounding world, profession, society, colleagues, family, and oneself (Ostanina \& Ostanin, 2019).

In the course of studying the psychological state and issues of harmonization, a number of conditions have been identified that have a significant impact on the teacher's activities: personal characteristics; process of interacting with learners in a social and emotional context; possession of professionally important qualities, including relevant skills and abilities; hopes placed on the teacher by the administration of the educational organization and society in general. These conditions can be divided into subjective (internal, determined directly by the subject) and objective (external, influencing the behavior of the subject and sometimes determining) factors.

The internal component, as a rule, includes type of temperament and its manifestation, prevailing attitudes and motivational orientation, character structure, distinctive features of the established image, appearance, etc. The external component now is even more complex in composition and has its own characteristics. The composition of the external component is largely determined by external environment of the activity, psychological state of the environment and society in general and it is supplemented by the established rules of activity (they are expressed in laws, orders and contracts), ethical standards and requirements for the quality of pedagogical work. A significant influence on the effectiveness of the teacher's activity is exerted by its demand by organization, state and society in general.

At present, disharmony is reflected in an intrapersonal conflict, when mutually exclusive rules and attitudes are opposed in a person, traditional ideas about the process are broken and the whole work activity becomes dependent on technical means and technologies. This leads to a decrease in the effectiveness of the teacher's activity and loss of motivation, which can negatively affect the entire learning process.

Despite the availability of information provided by various electronic educational and information resources on the Internet, the teacher's activities are not limited to the transfer of knowledge with their subsequent control, it also involves the implementation of the educational function (Ostanina \& Ostanin, 2017).

External factors also have a great influence. So, during COVID-19 pandemic, according to many experts, these factors had a decisive impact on the learning process. Their impact was direct on the teacher and was of an indirect nature, through an additional impact on students and administrative workers of educational organizations. 
Manifestations of the harmony of the teacher's personality, as an important factor in successful work, can be observed in the following manifestations:

- $\quad$ presence of measured way of life, which has a positive emotional color;

- physical and mental health;

- stable positive self-image;

- presence of variety of activities performed on a regular basis;

- absence of clearly inconsistent, antagonistic aspirations and presence of stable positive tendencies in self-development;

- adequacy of the assessment of claims and opportunities;

- generally positive assessment of their achievements;

- predisposition to cooperate with colleagues;

- spending time in nature regularly.

Thus, the events caused by COVID-19 made a significant contribution to the destabilization of the psychological state and contributed to the disruption of the harmony of the personality of teachers, which contributes to a decrease in the efficiency of their work, and, therefore, affects, along with the factor of technical support of the process and the quality of distance learning.

\section{Methodology}

The empirical data in this study were obtained by polling using a telecommunications network with a number of techniques. Online survey was conducted with a test that determines the level of depression on Beck scale, developed in 1961 by American psychotherapists led by Aaron Beck. It is based on the results of clinical observations that help to identify 21 symptoms of depression. The questions suggest four possible answers, one of which is chosen by the respondent. Each answer is assigned a certain number of points, and their total amount corresponds to the level of depression in a person.

Also, a study was conducted using the symptomatic questionnaire "Well-being in extreme conditions" by A. Volkov and N. Vodopyanova (Volkov \& Vodopyanova, 2013). It allows determining the predisposition to pathological stress reactions and neurotic disorders in extreme conditions according to the following symptoms of well-being: psychophysical exhaustion (decreased mental and physical activity), impaired volitional regulation, instability of the emotional background and mood (emotional instability), autonomic instability, sleep disturbance, anxiety, fears and addiction. The proposed questionnaire makes it possible to identify the characteristics of well-being in a given period of time by determining an unambiguous answer (yes/no) to 42 questions (Vodopyanova, 2013).

The assessment of the impact of the technical equipment of the participants on the educational process was carried out according to the developed questionnaire and assumed a comprehensive assessment of technical and software one. In particular, the 
need to adjust the learning process was assessed, taking into account the identified implementation difficulties caused by a sharp unplanned transition to a distance learning format.

Identifying the features of the psychological state of teachers caused by the pandemic, as well as assessing the factors of destabilization, allow identifying the most significant of them and developing recommendations for improving the psychological state of teachers and, as a result, improving the quality of the teaching process in emergency situations and situations close to them.

\section{Results and discussion}

As a result of the study, a significant influence of technical equipment on the learning process was revealed, however, the respondents noted the impossibility of a radical impact on this factor in the context of a sharp transition to a remote learning format and severe restrictions introduced in connection with the pandemic. However, the experience gained will allow in the future adapting to the situation in a shorter time frame. Also, $47 \%$ of respondents updated their technical devices after the removal of severe restrictions, which should also facilitate adaptation to the transition to a remote format of the educational process. $65 \%$ of respondents noted a significant increase in their competence in the information and communication field. Also, on the part of the teaching staff of the older age category, there was an increase in loyalty to the new format of education. However, the massive use of personal technical means also revealed the dishonesty of individual students, which was expressed in the concealment of true characteristics and availability of recommended technical equipment.

The results of using online survey to determine the level of depression on Beck scale during a pandemic indicate that the majority $(57 \%)$ of respondents are in a state of moderate depression. This state is characterized by immersion in melancholy, irritability, avoidance of communication and slight drop in self-esteem. $23 \%$ of respondents were exposed to a state of severe depression, which corresponds to a critical state in which a person loses interest in the world around him, lives and acts automatically, and not only emotional and psychological spheres, but also physical health suffer. About $5 \%$ of respondents in various periods of the imposed restrictions noted signs of a borderline state between moderate and severe depression, which was characterized by a feeling of hopelessness, abrupt and unpredictable mood changes. However, according to the respondents, they managed to cope with such manifestations through personal selfmobilization, reading classical literature and applying psychological practices.

As a result of the study using the symptomatic questionnaire "Well-being in extreme conditions" by A. Volkov and N. Vodopyanova (Volkov \& Vodopyanova, 2013), the majority $(63 \%)$ of the respondents showed an average level of psychological resistance to extreme conditions and a state of satisfactory adaptability. However, the respondents 
noted psychophysical fatigue (73\%), emotional instability $(23 \%)$, increased anxiety and fear (56\%), sleep disturbance (17\%) and autonomic instability (68\%).

In general, the psycho-emotional state of the professional group of teachers can be considered satisfactory. However, according to the results of surveys, it can be concluded that it is necessary to stabilize it and that it is necessary to use various psychological methods to improve the psycho-emotional state of teachers during emergency situations and situations close to them.

During COVID-19 pandemic, studies of the psycho-emotional state were carried out by a number of Russian and foreign researchers. Those who assessed the activities of employees of organizations transferred to a remote mode of work in comparison with employees who provide the vital processes of socially significant objects that remained with the previous mode of work are very interesting. Theoretical studies of a number of scientists confirm the conclusions about the negative impact of stressful situations on the implementation of learning process (Deineka et al., 2020; Kislyakov et al., 2020; Mikhailova \& Farennikova, 2020; Cherdakli, 2020).

\section{Conclusions}

The conditions of restrictions caused by the pandemic turned out to be close to the restrictions caused by emergency situations and situations close to them. The conditions of self-isolation in general contributed to the deterioration of the psychological state of the participants in the educational process, which is associated with many external and internal factors that influence teachers who are forced to carry out their work remotely.

The heterogeneity and lack of readiness of technical support can have a negative impact on the quality of the learning process, but it may not be possible to change anything in an emergency or close to it. Consequently, the most important will be the psychological state of the participants in the educational process and, first of all, of the teachers. Based on the study, a number of recommendations can be made for leveling the destabilizing factors:

- to increase the level of psychological stress resistance by conducting specialized trainings and game methods, during which to develop skills in assessing stressful situations and self-reflection;

- to identify and actively use methods of psychological support in teaching staff, including with the use of modern telecommunication means of communication;

- to optimize the loading system of teachers, taking into account their constant use of computer technology in the educational process and the sanitary standards of interaction with it;

- to develop normative acts and documentation regulating the activities of educators during emergencies and those close to them; 
- to reduce the monitoring of news on social networks and the media during and around emergencies to avoid increased stress levels caused by inaccurate information.

\section{References}

Abdalina, L.V. (2008). Psychological-acmeological model of teacher professionalism development. Tambov: Tambov State University named after G.R. Derzhavin.

Cherdakli, U.S. (2020). Features of the work of teachers in the distance learning system during the COVID-19 pandemic. World of Science, Culture, Education, 3(82), 278-280. Retrieved at: https://cyberleninka.ru/article/n/osobennosti-trudapedagogieskih-rabotnikov-v-sisteme-distantsionnogo-obucheniya-v-period-pandemiicovid-19/pdf

Deineka, O.S., Melnik, G.S., Dukhanina, L.N., \& Maksimenko, A.A. (2020). The psychological state of society in the context of infodemic. In Innovative development: the potential of science and modern education: a collection of articles of the VI International scientific and practical conference. Penza, 194-197.

Dubrovina, I.V., Danilova, E.E., \& Prikhozhan, A.M. (2019). Psychology. Textbook. Moscow: Academy.

Kislyakov, P.A., Shmeleva, E.A., \& Silaeva, O.A. (2020). Socio-psychological analysis of the safe pro-social behavior of Russians during a pandemic challenge. Methodology of modern psychology, 11, 139-149.

Mikhailova, O.B., \& Farennikova, E.S. (2020). Features of the psychological well-being of representatives of various professional groups during the COVID-19 pandemic. World of Science. Pedagogy and Psychology, 8(4), 54. Retrieved at: https://cyberleninka.ru/article/n/osobennosti-psihologicheskogo-samochuvstviyapredstaviteley-razlichnyh-professionalnyh-grupp-v-period-pandemii-covid-19/pdf

Nikiforov, G.S. (2002). Health psychology. Tutorial. St. Petersburg: Speech.

Ostanina, E.A., \& Ostanin, O.V. (2017). The activities of a university teacher in the context of the implementation of distance educational technologies. In Actual problems of the quality of education in higher education. Tver: Tver State Technical University. Retrieved at: https://www.elibrary.ru/item.asp?id=28814277

Ostanina, E.A., \& Ostanin, O.V. (2019). Personal harmonization as an element of professional development of a teacher of a modern university. Human capital, 3(123), 105-115.

Vodopyanova, N.E. (2013). Psychodiagnostics of stress. St. Petersburg: Publishing House "Peter".

Volkov, A., \& Vodopyanova, N. (2013). Symptomatic questionnaire: Well-being in extreme conditions. Retrieved at: http://deprimo.ru/psixodiagnostikastressa/simptomaticheskij-oprosnik-samochuvstvie-v-ekstremalnyx-usloviyax/

Volovikova, M.I., \& Dzhidaryan, I.A. (2017). Results of research on psychological health in the laboratory of personality psychology. Psychological journal, 38(2), 19-31.

Zinchenko, V.P. (2003). A large psychological dictionary. Moscow: OLMA Media Group. 